\title{
Jornalismo on-line no Brasil: reflexões sobre perfil do profissional multimídia*
}

\section{RESUMO}

Este trabalho visa contextualizar a emergência dos recursos multimidiáticos no jornalismo, explorar seu significado para a cultura profissional, as rotinas produtivas e o ambiente de trabalho. Fazemos uma reflexão sobre como todos esses elementos estão mudando o panorama das mídias contemporâneas, em especial o perfil do jornalista. Enquanto procuramos estabelecer uma moldura conceitual para os fenômenos, provemos uma síntese dos debates que estão sendo realizados neste momento no mundo. Buscamos ainda guiar a discussão para o currículo dos cursos de Jornalismo e as novas competências que se exigem dos profissionais. Entendemos assim que há necessidade de um consenso mínimo entre os atores direta ou indiretamente envolvidos com o processo de produção noticiosa, em um cenário de computadorização, digitalização e convergência das organizações jornalísticas.

\section{PALAVRAS-CHAVE \\ jornalista multimídia \\ jornalismo on-line \\ ensino do jornalismo}

\section{ABSTRACT}

This paper seeks to contextualize the emergence of multimedia resources on journalism and to explore its meaning to professional culture, to productive routines and work environment. We did a reflection about how these elements are changing the scenario of actual media, specially the journalist profile. While we look for establishing a conceptual approach for these phenomenons, we synthesize the debates realized at this moment worldwide. We also look for guide these discussions for Journalism graduate program and the new skills required from these professionals. Therefore, we understand that on a context of computing, digitalization and convergence of journalistic organizations in Brazil, there is no need for a minimal consensus between the social actors directly and indirectly related to new production process.

\section{KEY WORDS}

multimedia journalism

online journalism

journalism teaching

\section{Thaís de Mendonça Jorge \\ Doutora em Comunicação pela UnB/DF/BR \\ thaisdemendonca@vol.com.br}

\section{Fábio Henrique Pereira}

Doutor em Comunicação pela UnB/DF/BR

fabiop@gmail.com
A expressão jornalismo multimídia vem sendo usada como tema de congressos, palestras e seminários no Brasil e no exterior. Premido pela convergência tecnológica, pela propriedade cruzada dos meios de comunicação e pelas redações integradas, o jornalismo multimidiático está no centro de muitas das preocupações das empresas, dos próprios jornalistas e das escolas de Comunicação. Ele também pode ser denominado e-journalism, ciberjornalismo, jornalismo on-line ou jornalismo na internet, embora esses novos nomes mostrem ligeiras diferenças de atributos entre si.

Para esclarecer e contextualizar a emergência dos vários recursos midiáticos no jornalismo, explorar as suas múltiplas significações para a cultura profissional, para as rotinas produtivas e para o ambiente de trabalho, fazemos, neste trabalho, algumas reflexões sobre como todos esses elementos trazem severas mudanças no panorama das mídias contemporâneas. Procuramos estabelecer uma moldura conceitual para os fenômenos e, ao fazê-lo, provemos uma síntese dos debates que estão se dando neste momento no mundo, em especial na América Latina. Nesse sentido, buscamos também guiar a discussão para o currículo dos cursos de Jornalismo e para as novas competências que se exigem dos profissionais.

\section{0 que é o jornalismo multimídia?}

Podemos começar perguntando: o que é o jornalista multimídia? O que faz um jornalista ser multimídia? Qual o lugar do profissional multimídia? Em latim "media" é o plural de "medium". Multi (do latim significa muito, numeroso, abundante) + media seria, então, uma multiplicidade de meios. No dicionário (Ferreira, 2004, p. 372), multimídia é a "apresentação de informações em uma multiplicidade de formatos, ou o conjunto de informações assim apresentadas". Díaz Noci e Salaverría (2003, p. 120) estabelecem o paralelo entre a digitalização - definida como "uma linguagem de uns e zeros" - e a multimídia. "Quando esses suportes se reúnem em mensagens únicas compõem o que se chama multimídia: uma integração sincrônica e unitária de conteúdos expressados em diversos códigos, principalmente mediante textos, sons e imagens".

Para os autores, a partir dessa conceitualização tecnológica, avança-se para uma idéia mais abrangente, dando lugar a um resultado lingüístico cuja capacidade evocadora vai além da mera soma dos elementos icônicos, textuais e sonoros, pois, "na multimidialidade, $1+1+1$ soma algo mais que 3 ". Já Torres e Amérigo (2003, p. 73), definem multimídia como o "suporte digital [que] permite falar mais que 
de um meio, da multimídia entendida como uma integração dos demais meios conhecidos: imprensa escrita, rádio, TV".

Apesar das definições funcionais apontarem para o acertado uso do termo multimídia no campo da comunicação, hoje em dia ele é utilizado para um semnúmero de designações: nos programas Big Brother, passando por salas de cinema multimídia, até os profissionais multitarefas - mulheres e homens de qualquer área profissional, que dão conta de diversos trabalhos e arranjos a um só tempo. Observamos que a enunciação jornalismo multimídia desata três ordens de preocupações dando, por sua vez, origem a outras indagações:

a) nas empresas - as organizações estão preocupadas em "não perder o bonde da história", ou seja, não serem ultrapassadas pela onda tecnológica. Isso foi o que as fez partir em direção à internet nos anos 1990, atendendo a um movimento mundial, mesma atitude que levou muitos empresários a aderir à bolha da internet, em 2000, e a gerar iniciativas pontocom. O questionamento das instituições midiáticas no processo de absorção da multimidialidade teria dúvidas como: como tirar partido das inovações para se expandir e não perder leitores? Como explorar os recursos humanos e tecnológicos e obter retorno dos investimentos?

b) nos jornalistas - de acordo com estudos recentes, os profissionais das redações registram inquietações relacionadas à própria identidade e papel, não só no ambiente de trabalho, como também diante da sociedade. No recôndito de sua sala ou, em muitos casos, na própria casa ou em um exíguo canto de uma sala de imprensa, o profissional do jornalismo se faz a pergunta: devo estar o tempo todo conectado? Vou ser suplantado por um repórter mais novo? Devo me tornar um super-especialista?

c) nos acadêmicos/ professores - as escolas, como sempre, encontram-se divididas entre formar o jornalista para o mercado, fornecer instrumentos aos estudantes para criticar as instituições jornalísticas, ou incentivar a pesquisa. Nesse sentido, as questões seriam: qual o perfil do jornalista hoje? O que oferecer aos alunos, nos currículos e programas das disciplinas? Como incorporar as tecnologias ao processo de ensinoaprendizagem? Onde encontrar professores para as novas áreas do jornalismo?

Dentro dessa linha, Mark Deuze (2004) propõe a noção de "multimedia logic" para observar a mídia sob as perspectivas da competência institucional, tecnológica, organizacional e cultural e que envolve também o produtor e o usuário. Ele defende que esse conceito permite ter uma visão ampla da dinâmica de mudança e resistência à adaptação no novo ambiente. Deuze situa o estudo dentro das fronteiras de certo tipo de mídia e que permite ainda analisar as características dos profissionais dos meios de comunicação em termos de como eles descrevem e avaliam competências, atributos e desempenho.

Apesar das definições funcionais apontarem para 0 acertado uso do termo multimídia no campo da comunicação, hoje em dia ele é utilizado para um sem-número de designações: nos programas Big Brother, passando por salas de cinema multimídia, até os profissionais multitarefas

Deuze (2004) trabalha, na verdade, um conceito pragmático de jornalismo multimídia. Ele evidencia a distinção deste com o jornalismo on-line, ou seja, realizado no âmbito das redes de computadores. Para o pesquisador holandês, o jornalismo multimídia é produzido num contexto digital, inclui áudio, vídeo e texto, e sua destinação é "mais ou menos exclusiva" para apresentação e distribuição na WWW, tendo uma interface gráfica na internet.

\section{Mudança genética}

Muitos estudiosos vêm reiterando que a chegada de novas tecnologias implica em alterações no modo de vida, no que chamamos, em outro trabalho (Jorge, 2007), de um processo de mutação. No nosso caso, a mutação incide diretamente a notícia ${ }^{1}$, bem como sobre seu mecanismo de produção, os agentes e as empresas informativas. Sabemos que as grandes mudanças (genéticas, nessa comparação) provocam sucessivas alterações nas características - ou no DNA do jornalismo - e isso não se dá sem conflitos e tensões. Seja qualificado como jornalismo on-line, digital, ciber ou e - jornalismo, seja acompanhando as causas dos cidadãos no jornalismo cívico ou comunitário, o que nos importa neste trabalho é delimitar as fronteiras dessa atividade praticada, por jornalistas, com recursos multiplataforma, no ambiente das redes de alta velocidade. E, falando do referencial teórico que a explica e conceitua, estamos também tratando das outras facetas dos estudos de newsmaking.

Deuze (2004, p. 142) foi um dos que se preocuparam com os três vértices do jornalismo multimídia - a empresa (meio de produção), o trabalho (rotinas produtivas) e o jornalista (identidade profissional). Ele reporta tentativas de convergência experimentadas, 
por exemplo, pela BBC de Londres, que instituiu o Combo Journalism colocando nas mãos dos repórteres, em meados do século XX, câmeras fotográficas. "Numa perspectiva organizacional, a convergência vem com diferentes formas e tamanhos, grandemente influenciada por fatores internos (práticas, rituais, rotinas, culturas), bem como externos (regulação, competição, apoiadores, público)".

Para as empresas, a multimidialidade - vista como inexorável no panorama atual das mídias, para os grandes como para os pequenos empreendimentos - representa investimento de vultosas somas em equipamentos, hard e software e constante atualização ("para não perder o bonde da história"). Todavia, no que concerne ao trabalho, muitos jornalistas que trabalham em empresas convergentes, "sentem que o motivo primário para a convergência e a junção ou cooperação entre mídias é a economia de dinheiro", conforme frisou Deuze (2004, p. 143), fazendo referência ao trabalho de Singer (2004).

Ao recorrer a uma pesquisa de Devyatkin (2001 apud Deuze 2004, p. 143), Deuze explica que "os executivos da nova mídia tendem a vê-la como uma maneira de diminuir o tamanho da folha de pagamentos: fazer mais com menos gente - e não como uma maneira de explorar novos gêneros, estilos, ângulos ou fontes para as notícias". Assim, a convergência no nível das empresas provoca pressões no nível individual (responsabilidade e ética no processo de tomada de decisões), na escolha e diversidade das fontes utilizadas, além da aceleração dos processos.

De acordo com o estudo Hábitos de trabalho do jornalista latino-americano, publicado pela Fundação Konrad Adenauer e pelo Instituto Imprensa e Sociedade, os profissionais das redações de 11 países - Argentina, Bolívia, Chile, Colômbia, Equador, Guatemala, México, Paraguai, Peru, Uruguai e Venezuela - têm alguns pontos em comum: "Trabalham em tempo integral. Têm menos de quatro horas para entregar seus textos. São jornalistas mais de escritório que de rua".

Os jornalistas tendem a reclamar de mais trabalho, com o mesmo salário. A exploração da mais-valia, junto com o fechamento contínuo das páginas na internet, causa estresse e frustração e sentimentos de ansiedade, desconfiança e até desrespeito entre colegas de mídias convergentes. Em pesquisa realizada no jornal O Globo, ouvimos de um jornalista da redação impressa a expressão "cabeça de alfinete", para se referir aos companheiros do on-line, numa alusão a cérebros possivelmente menores (por causa do uso da tecnologia) e a um penteado de cabelos tosados, bem à moda dos jovens.

O cenário de mutação que incide sobre as organizações informativas, modificando a cultura profissional - do legs'man (o homem das pernas, o repórter) do passado, ao "jornalista sentado" (Pereira, 2004) - das redações multimídia, altera-se as habilidades exigidas aos profissionais. No portal UOL, como em qualquer veículo do Grupo Folha de São Paulo, as qualidades do "jornalista de internet" apontadas por um dos dirigentes da empresa são: “Boa formação cultural, bom texto, domínio excelente do português escrito, uma língua, de preferência o inglês". À formação, acrescentam-se dados específicos: "Que [o profissional] não tenha preconceito nem dificuldade com internet, nem com equipamentos e software novos. Que tenha curiosidade, disposição para aprender, enfrentar novas tecnologias e gadgets. Não pode ser estranho a nenhuma tecnologia".

Outro líder de produção do site destaca que se deve "ser mais editor que repórter, mas que se esteja apto a fazer matéria quando precisar", e sinaliza para outros atributos pessoais: "ter pique", "e o mínimo de um jornalista comum: saber o que é notícia" (Jorge, 2007). Entretanto, se a destreza tecnológica não é um pré-requisito na decisão de contratar novos jornalistas - e sim a vontade de aprender e, ao lado disso, a disposição em explorar as tecnologias -, a ausência de preconceito quanto a novos métodos e, principalmente, a habilidade de entender e pensar, relacionando diversos conhecimentos é que vêm sendo uma espécie de trunfo dos jornalistas para o século XXI.

$\mathrm{O}$ editor de Economia da Folha Online, Tony Schiaretta, ressalta que o jornalista multimídia concentra uma "fusão de funções: chefe de reportagem, editor, repórter, paginador":

A essência da prática jornalística não mudou. $\mathrm{O}$ bom jornalista continua sendo aquele capaz de apurar uma boa matéria, escrever um bom texto, fazer um bom título. Aquele que dá a informação rápida, objetiva, crítica, pluralista e independente. O papel do jornalista multimídia se expande, ele se torna mais flexível e completo, exige novas habilidades. Para trabalhar na internet, ele precisa ousar e tentar novas formas de comunicar; conhecer as especificidades do meio, entender e aprender a usar as ferramentas; ser cada vez mais um contador de histórias (Schiaretta, 2006).

É mais ou menos o pensamento de Pablo Marmorato, jovem jornalista do Clarín Global, o braço on-line do jornal argentino Clarín:

Hoje, o jornalista tem que fazer de tudo um pouco. Não há mais diferenças entre um fotógrafo, um cinegrafista, um redator. Parece que a realidade obriga todos a incorporar novas ferramentas. O jornalista multimídia tem que entender de tudo, até de desenho gráfico. Tem que ser capaz de editar uma foto, de editar um vídeo, um podcast. Creio que é também uma questão de custo para as empresas. Em vez de mandar uma equipe de quatro pessoas para cobrir uma guerra, agora mandam só uma [...] que vai cobrir a invasão do Iraque com uma câmara 
e um telefone via satélite. E produz quatro informes por dia (Jorge, 2007).

Os contornos de todo esse cenário e a indefinição quanto ao papel do jornalista hodierno fazem ressurgir antigos dilemas da profissão (técnica versus formação intelectual) e demonstram como velhos valores tendem a moldar percepções e usos sobre as tecnologias. No caso do jornalismo multimídia, o perfil ideal, longe de excluir o domínio técnico, busca uma conciliação entre os dois pólos da identidade jornalística: "Aprender a pensar criticamente é importante para os estudantes, mas a escrita multimídia e a as competências produtivas são igualmente importantes, sobretudo quando isso aparece completamente resolvido na formação do jornalista: estórias bem contadas e balanceadas para o público, produzidas nos diversos formatos noticiosos que o leitor pretende acessar atualmente" (Huang et al., 2006, p. 94).

\section{Desafio acadêmico}

Até alguns anos atrás, o mercado era o principal espaço de formação do jornalista. "Aprendia-se nas redações, nas oficinas, no botequim do outro lado da rua, nas noitadas de sexta-feira. O jornal todo era uma fábrica que formava e informava sem equívocos e gerava opinião num ambiente de participação [...]", constatava Gabriel García Márquez (1997, p. 46).

Da recorrente tensão entre formação teórica e prática, entre um jornalista crítico e um bom técnico, surgem problemas em torno da estruturação do currículo e da busca e adaptação de uma bibliografia pertinente para o ensino do jornalismo (Mackinnon, 2008). Essa tensão passa ainda pela formação de quadros no corpo docente que possuam adequada base teórica e experiência profissional em redações multimídia. Ora, seria no mínimo ingênuo acreditar que as adaptações feitas por conta do jornalismo pós-internet tenham dado conta desses problemas. Todo esse questionamento parece, enfim, ter sido reapropriado e reinserido na pauta de discussões sobre a formação profissional do jornalista e deve ganhar nova dimensão com o fim da obrigatoriedade do diploma para o exercício profissional, no Brasil.

Numa pesquisa publicada em 2006, João Canavilhas explica que, em Portugal, 53,7\% dos jornalistas que trabalhavam em redações on-line foram treinados pelas próprias empresas; $26 \%$ dos entrevistados adquiriram suas competências em faculdades ou escolas e $33,3 \%$ não receberam qualquer tipo de aprendizado sobre jornalismo on-line ou multimídia. A pequena participação das instituições de ensino superior na formação dos jornalistas explica-se, em parte, pela falta de docentes especializados em jornalismo digital.

Pesquisa feita nas bases de dados do Instituto Nacional de Estudos e Pesquisas Educacionais Anísio Teixeira (Inep/MEC) em 2006, por ocasião do Exame
Nacional de Desempenho de Estudantes (Enade), mostra que apenas 68 professores vinculavam sua atuação a áreas como jornalismo digital, on-line, multimídia, na internet ou ao ciberjornalismo. Isso daria uma média de quase 154 alunos por professor. Hoje, a proporção é possivelmente menor. De fato, vários pesquisadores que vinham realizando dissertações e teses nessas áreas ingressaram como professores de cursos de jornalismo, o que se reflete na quantidade de trabalhos acadêmicos e de experiências docentes.

Além disso, observamos a criação de cursos integrados à nova realidade ou a adaptação de antigos currículos ao perfil exigido pelo mercado. Um relatório da Red Iberoamericana de Comunicación Digital $\left(\operatorname{Icod}^{2}\right)$ classifica a apropriação das tecnologias digitais pelos cursos de Comunicação a partir de três cenários distintos:

I) Cursos tradicionais atualizados, vinculados a instituições públicas ou a universidades com grandes estruturas de ensino e com dificuldades de assimilar as mudanças. No caso, o processo de digitalização é introduzido por meio de matérias teóricas ou práticas optativas, incluídas no final dos cursos;

II) Cursos redesenhados, que sofreram reformas mais profundas para a introdução transversal de conteúdos relacionados aos processos de digitalização e às práticas multimídia;

III) Novos cursos, criados já dentro dessa lógica transversal e que incorporam as novas tecnologias no momento de definição da grade curricular.

Apesar da assimetria no processo, pode-se inferir que a participação das universidades na formação de jornalistas adaptados ao mercado multimídia tem crescido. Debates sobre o caráter transversal do ensino especializado estão começando a aparecer no Brasil. Ao lado de disciplinas puras para o ensino e a prática de comunicação digital e do webjornalismo, iniciativas de aplicação de recursos on-line no ensino de jornalismo promovem seu início, às vezes de maneira tímida, às vezes em caráter experimental, nas universidades brasileiras como nas latino-americanas. Isso facilita, por um lado, a inserção dos futuros profissionais e reduz a pressão nas empresas para treinamento relacionado às competências do jornalismo multimídia.

Por outro lado, parece importante não desprezar o conhecimento que pode ser adquirido na prática profissional, buscando-se aliar as duas formações. "Muitas oportunidades existem para companhias noticiosas e universidades que trabalharem juntas para explorar a questão da convergência midiática e fornecer treinamento em multiplataformas tecnológicas para profissionais já empregados e editores" (Huang et al., 2006, p. 94). Roush (2009) conta que essa parceria foi utilizada pelos alunos de mestrado Universidade do Alabama (Estados Unidos), na aplicação de métodos de jornalismo multimídia, para a cobertura de assuntos 
de interesse da comunidade. Segundo o autor, esse “jornalismo-público-multimídia" levou a um diálogo entre as culturas da redação e do meio acadêmico e impulsionou a inserção profissional dos egressos daquela universidade.

Mesmo que não haja ainda um método consolidado para o aprendizado do jornalismo multimídia nas universidades, podemos apontar alguns avanços a partir de experiências docentes realizadas nos últimos tempos. Os dados da Rede Icod mostram que existe um processo difuso de incorporação dos novos conteúdos digitais aos cursos superiores de Jornalismo no Brasil. Matérias introdutórias, de caráter geral, sobre as tecnologias da comunicação e da informação na sociedade convivem com disciplinas que estimulam a criação de produtos multimídia, a partir da aplicação dos instrumentos tecnológicos adequados à comunicação digital.

O relatório Icod cita ainda a existência de disciplinas instrumentais - sobretudo no uso de computadores e de conteúdos teóricos sobre o uso da comunicação digital dentro de uma perspectiva reflexiva. A introdução de experiências pedagógicas do tipo weblog, com a colaboração ou não dos alunos -, a criação de parcerias entre escolas e mercado são, contudo, iniciativas isoladas dentro de um meio acadêmico e laboral marcado pela precarização dos profissionais e pelo improviso no ensino e no desenvolvimento de práticas mais adaptadas à nova realidade. Trazer esse debate à tona pode ajudar a situar melhor o papel do jornalista multimídia e prepará-lo para enfrentar as mudanças.

\section{Considerações finais}

No presente artigo, deixamos de lado as questões de recepção para nos concentrar nos produtores, os jornalistas. Nossa intenção era a de examinar o contexto no qual se dá a irrupção da multimídia no jornalismo. Desse modo, procuramos abordar seu significado para a cultura profissional, e nos deter na sociologia dos produtores, ao refletir sobre as rotinas produtivas e o ambiente de trabalho, nas redações que exercitam a convergência dos meios digitais. Buscamos apontar como todos esses fatores estão transformando o cenário midiático contemporâneo e afetam notadamente o perfil do jornalista. Retornando às três ordens de preocupação a que aludimos no início, podemos concluir que:

a) do ponto de vista das empresas - elas tem que ser capazes de organizar pessoas em times ou grupos, e gerenciar essas pessoas em projetos, arranjos produtivos, num modo colaborativo e que permita o cruzamento das diversas seções da empresa, pois, como dizem os especialistas, o discurso otimista sobre as competências do jornalismo multimídia se centra em conceitos como flexibilidade, habilidades de trabalhar em grupo, o valor da comunicação e do entendimento dos objetivos, necessidades e demandas das outras mídias;

b) dos jornalistas - trata-se da mudança de um fazer jornalístico individualizado, comum nas redações do passado, para um jornalismo em equipe. A identidade profissional do jornalista multimídia ainda está em processo de negociação e avaliação, e sofre a influência de vários fatores. No processo de tomada de decisão do repórter acerca das fontes a consultar ou na adoção e utilização da tecnologia por toda a redação convergente, o que está em jogo é a identidade profissional do jornalismo, num environment of service em mutação onde se questionam princípios de hierarquia e autoria;

c) dos acadêmicos/professores - as escolas brasileiras de jornalismo sabem que o mercado não se interessa hoje apenas por indivíduos com formação técnica, mas "exige que tenham capacidade de enfrentar desafios, de empreender, de trabalhar em grupo, de renovar constantemente seus conhecimentos" (Dimenstein, 2007). Essa preocupação já está presente no novo Exame Nacional do Ensino Médio, que vai direcionar e influenciar o novo vestibular para as universidades públicas no Brasil. Na perspectiva da elaboração dos currículos de jornalismo, os estudiosos sinalizam para a importância de compreender "a lógica da mídia" (Deuze, 2004), de introduzir a crítica em todos os aspectos do ensino das disciplinas ligadas à multimídia e permitir que a convergência seja contestada. Talvez prestando mais atenção na qualidade da interação entre jornalistas, educadores, estudantes de diferentes meios (rádio, TV, jornal, revista, web), como também nas outras facetas da comunicação - nas relações públicas, marketing, comunicação estratégica - se possa esperar uma verdadeira transdisciplinaridade.

E é justamente esse caráter transversal que precisa ser incentivado na aplicação do jornalismo multimídia a partir da formação nas universidades, a fim de que os profissionais saídos desse ambiente não vejam uns aos outros como competidores, mas como colegas. Entendemos que há uma necessidade absoluta de consenso entre essas três vertentes do mesmo processo, a fim de que as dificuldades de ensino, pesquisa e de mercado possam ser integradas e satisfeitas num esforço coletivo

\section{NOTAS}

* Texto apresentado no XXXII Congresso Brasileiro de Ciências da Comunicação (Intercom).

1 Ver Jorge (2007): “A mutação no jornalismo, é uma repentina mudança no estado de percepção, captação e processamento dos fatos - que são o DNA da notícia -, o que provoca diferenças nas rotinas, nos produtos e subprodutos.[...] Tal como na natureza podem ocorrer mudanças no estado dos seres vivos, a notícia hoje: (a) muda do estado "sólido" 
para o estado virtual; (b) em termos de composição, agrega novos produtos, como ciberentrevistas e flashes; (c) as propriedades são alteradas (não tem mais as cores do papel, mas as cores de uma tela eletrônica; não pode mais ser manuseada, deve ser apenas vista, ouvida ou assistida); e (d) há uma mudança na energia, quando a capacidade de fazer o trabalho, pelos jornalistas, passa a ser pressionada pela velocidade."

2 A rede Icod foi criada em 2003 com o objetivo de elaborar propostas concretas que acelerem a adaptação dos cursos da área de Comunicação à nova realidade digital. Integram a rede universidades na Espanha, Argentina, Portugal, Cuba, Brasil, França e Itália. Outras informações, no site: <http://www.icod.ubi.pt/home.html>.

\section{REFERÊNCIAS}

CANAVILHAS, João Manuel Messias. Do jornalismo online ao webjornalismo: formação para mudança. Biblioteca On-line de Ciências da Comunicação, 2006. Disponível em: <http:/ / www.bocc.ubi.pt/pag/ canavilhas-joaojornalismo-online-webjornalismo.pdf $>$.

DÍAZ NOCI, Javier. La escritura digital. Hipertexto y construcción del discurso informativo en el periodismo electrónico. Bilbao: Universidad del País Vasco, 2001.

DÍAZ NOCI, Javier; SALAVERRÍA ALIAGA, Ramon. (Coords.) Manual de redacción ciberperiodística. Barcelona: Ariel, 2003.

DEUZE, Mark. 'What is Multimedia Journalism?' Journalism Studies, v. 5, p.139-152. In: $<$ http://convergence.journalism.indiana,. edu/media/documents/Convergence/ DeuzeMultimedia.JS.pdf.> Acesso em 26 jun. 2009.

DIMENSTEIN, Gilberto. Você compraria uma máquina de escrever? Folha de S. Paulo, 30. set. 2007.

FERREIRA, Aurelio Buarque de Holanda. Novo dicionário da língua portuguesa. Rio de Janeiro: Nova Fronteira: 1986.

GARCÍA MÁRQUEZ, Gabriel. A melhor profissão do mundo. Caros Amigos, abril 1997, p. 46.

HUANG, Edgar; DAVISON, Karen; SHREVE, Stefanie; DAVIS, Twila; BETTENDORF, Elizabeth. NAIR, Anita. Facing the Challenges of Convergence: Medias Professionals Concerns of Working Across Media Platforms.
Convergence: The International Journal of Research into New Media Technologies, v. 12, 2006, p. 83-98.

JORGE, Thais Mendonça. A notícia em mutação. Estudo sobre o relato noticioso no jornalismo digital. Tese (Doutorado em Comunicação), Universidade de Brasília, 2007.

MACKINNON, Rebecca. Teaching multimedia journalism: online resources - many of them free of charge - are used as the textbooks for training the next generation of journalists. Nieman Reports, p. 93-96, primavera 2008.

PEREIRA, Fabio Henrique. O jornalista sentado e a produção da notícia on-line no Correioweb. Revista em Questão. Porto Alegre, v. 10, n. 1, p. 95-108, 2004.

ROUSH, Chris. Moving the classroom into the newsroom: the Anniston Star's creative model for partnership between news outlets and educational institutions. American Journalism Review, p. 42-48, fev./mar. 2009.

SCHIARETTA, T. Qualidade editorial em um mercado multimídia. In: Seminário Internacional Imprensa Multimídia/ as redações de terceira geração, 2006, Brasília.

TORRES, Elvira; AMÉRIGO, Maria Pou. Características de la comunicación digital. In: DÍAZ NOCI, J.; SALAVERRÍA, R. (coords.). Manual de redacción ciberperiodística. Barcelona: Ariel, 2003. 